\title{
LA PRODUCCIÓN ESCRITA DE LA MISERICORDIA DE VILA VIÇOSA (1510-1910)
}

\author{
María Marta LOBO DE ARAÚJO \\ Departamento de História. Universidade de Minho-Portugal
}

Recibido: 08/02/2013

Aceptado: 04/11/2013

RESUMEN: Nuestro estudio analiza la producción escrita de la Misericordia de Vila Viçosa a lo largo de cuatro siglos y pone de relieve el marco en el que fue llevada a cabo, así como las personas encargadas de ello. El análisis a largo plazo permite conocer no solo los diversos marcos reglamentarios sino también los diferentes contextos de la producción escrita.

Aunque la documentación que se conserva no recoge todas las series de libros producidas, constituye un volumen considerable de fuentes a través de las cuales se ha podido construir la historia de la Santa Casa.

PALABRAS CLAVE: Producción escrita, fuentes, Misericordia, Vila Viçosa.

ABSTRACT: Our study examines the writing of the Misericordia of Vila Viçosa over four centuries, as well as people in charge of producing. The analysis in the long term allows knowing the different determinations and writing skills of the actors.

The documentation that is conserved is not part of all books produced, but it is a considerable amount of sources through which it was possible to construct the story of the Holy House.

KEYWORDS: written production, sources, Misericórdia of Vila Viçosa.

\section{INTRODUCIÓN}

Analizar un período de cuatro siglos de la vida de una institución se hace comparando no sólo lo que permanece, sino también lo que cambia en todos los sectores. La Misericordia conoció muchas transformaciones y sus escritos no estuvieron exentos de variaciones.

El cofrade encargado de registrar la vida de la cofradía tenía su función establecida por las normas en vigor. La Santa Casa de Vila Viçosa (Alentejo) estuvo gobernada entre 1510 y 1910 por cuatro «compromissos» en 1516, 1577 (adaptado a la cofradía alentejana), 1618 (entre 1806 y 1881) y en 1881, modificado en 1899. 
Actualmente el archivo de la Santa Casa está dividido y custodiado en dos instituciones: la Cámara Municipal y en la propia Misericordia. El Archivo Municipal conserva documentación desde el siglo XVI hasta el XIX y en la cofradía permanecen obras del siglo XVIII y todo el acerbo de los siglos XX y XIX. Los fondos custodiados en la Cámara están custodiados y reseñados, pero lo que se encuentra en la Santa Casa continúa esperando ese trabajo. Esa situación en nada favorece su protección y contribuye a que el espolio en su conjunto no esté debidamente acondicionado y conservado ${ }^{1}$.

\section{LA PRODUCCIÓN ESCRITA Y LOS ESCRIBANOS}

La elección del cofrade escogido para escribano en las Santas Casas era realizada el día de las elecciones y se respetaba lo determinado en los estatutos. Después del nombre del cofrade proveedor, se elegía al escribano ${ }^{2}$. La selección era nominal y hecha para determinada función.

En el texto de 1516, aunque no se explicasen las funciones del escribano y la constitución del archivo, se hacía referencia a los libros que deberían existir: uno para los ingresos y gastos, con secciones separadas, y otro donde el mayordomo externo registraba algunos pagos, aunque también se asentaban los presos asistidos y las limosnas dadas a los pobres ${ }^{3}$.

Las indicaciones para registrar eran pocas y se referían solo a dos sectores: organización interna, que abarcaban los ingresos, los gastos y los pagos efectuados por algunas personas, y el sector de caridad, ayuda a presos o envío de limosnas.

Como la institución estaba comenzando no exigía una contabilidad escrita como se producirá después, aunque se procuraba dejar apunte de los sectores más importantes de su actividad. A medida que se fue desarrollando, se hizo necesario adaptar las reglas existentes y en 1577 el acuerdo de 1516 fue reformado.

Ese acuerdo presenta algunas diferencias con relación al de la Misericordia de Lisboa del mismo año. Permanecen todavía las obras de misericordia en el primer

\footnotetext{
${ }^{1}$ A propósito de las condiciones en las que se encuentran algunos archivos de las Misericordias véase Penteado, P., (1998). «Os arquivos e a História das Misericórdias em Portugal: problemas e perspectivas». Oceanos, n ${ }^{\circ} 35$, pp. 91-96.

2 Do Compromisso da confraria da Sancta Caza da Misericórdia de Lisboa fundada pela rainha D. Leonor de Lencastre. (1929). Caldas da Rainha: Tip. Caldense, p.21; Arquivo Municipal de Vila Viçosa (de aqui ren adelante AMVV), Fundo da Misericórdia, Compromisso de 1577, Livro n²2, fl. 10 .

${ }^{3}$ Do CомрRomisso da confraria da Sancta Casa da Misericórdia de Lisboa fundada pela Rainha D. Leonor de Lencastre..., pp. 29-30.
} 
capítulo, a semejanza del de 1516, pero ya no figuran en el de la Santa Casa de la capital, y tiene algunos capítulos con otra disposición.

No deja de ser significativo que el número de libros registrados en el acuerdo de 1577 de la Misericordia de Vila Viçosa sea superior al referido en el texto de la misma fecha del de su análogo de Lisboa ${ }^{4}$. Existen todavía algunas diferencias respecto a las directrices para hacer los asientos. En el texto de Vila Viçosa se recogen en el capítulo de los libros y en el de Lisboa se desarrollan a lo largo de varios capítulos. Se trata solamente de diferencias formales que no difieren en el contenido del documento de la Misericordia de Lisboa.

El acuerdo de 1577 de la Santa Casa de la villa alentejana fue copiado en 1661 porque se encontraba en malas condiciones. Fue el texto que estuvo más tiempo en vigor en esa institución. Al final de los capítulos contiene algunos acuerdos, a semejanza de lo verificado en el de 1577 , aunque no todos hayan sido trasladados a la copia de 1661 .

El cofrade elegido para escribano pertenecía a la nobleza y cuando el proveedor estaba impedido, «actuaba en su lugar el escribano de la casa y en el caso de muerte u ocupación del servicio del duque, nuestro señor, o por cualquier otro caso, que no pudiera hacerlo a tiempo durante el año», el escribano y los otros miembros de la junta convocaban al proveedor del año anterior. En el caso de que este no aceptase, se recurría a su antecesor y así sucesivamente hasta encontrar un cofrade que aceptase el cargo ${ }^{5}$. Los electores se reunían para elegir otro cofrade en el caso de que ninguno aceptase.

Situada en la sede de la Casa de Bragança y con una relación muy estrecha con los duques, la Misericordia introdujo en el acuerdo una cláusula que exigía preferencia para la prestación de servicios a la Casa de Bragança. Así sucedió a finales del siglo XVI y primeras décadas del siguiente cuando algunos de los elegidos para la proveeduría y para otros cargos de la Junta no podían aceptar el cargo por estar al servicio del duque ${ }^{6}$.

\footnotetext{
${ }^{4}$ Véase Paiva, J. P. (coord. científico) (2005). Portugaliae Monumenta Misericordiarum. Vol. 4. Lisboa: Centro de Estudos de História Religiosa; União das Misericórdias Portuguesas, p.354.

${ }^{5}$ AMVV, Fundo da Misericórdia, Compromisso de 1577, libro nº 22, fl. 11.

${ }^{6}$ Véase ARAúJo, M. M. L. (2000). Dar aos pobres e emprestar a Deus: as Misericórdias de Vila Viçosa de Ponte de Lima. Barcelos: Santa Casa de Misericórdia de Vila Viçosa e Santa Casa da Misericórdia de Ponte de Lima, pp. 91-94.
} 
Esto ocurre porque muchos proveedores pertenecían a esta Casa señorial y por ser hombres muy próximos al duque ${ }^{7}$.

La interferencia directa de los duques en la vida de la Santa Casa venía de lejos, tal vez desde la fundación, y todavía estaba asociada al hecho de ser ellos sus principales bienhechores. Atentos y vigilantes, los duques trataban la Misericordia como propia, colocando los hombres designados por ellos incluso en los principales puestos de la cofradía y controlando la continuidad de sus grupos sociales.

Como refiere Mafalda Soares da Cunha, la política seguida por la Casa de Bragança tenía tendencia a usar «liberalidad para armonizar relaciones interpersonales a través de cambios y de negociaciones de los distintos intereses en juego»» ${ }^{8}$.

Estando impedido el proveedor, el escribano asumía sus funciones y otro miembro de la junta era designado como escribano durante la ausencia del titular. El texto del compromiso de 1577 establecía que el escribano fuese cofrade «honrado y virtuoso, de buena fama, casado o que lo haya sido, con la edad de cuarenta años (...) muy humilde y paciente ${ }^{9}$. Se le exigía un carácter de virtud y honradez, lo cual le confería autoridad. Debía frecuentar la institución con regularidad y estar presente en las reuniones de la Junta (domingos y miércoles). Era el encargado de todos los escritos de la cofradía y tenía que hacerlos de «propia mano», pues estaba prohibido por los estatutos dejar escribir en los libros de registro a otra persona. Cuando un miembro de la junta ejercía las funciones de escribano, hacía las anotaciones en un cuaderno y el titular las pasaba posteriormente a los respectivos libros. Era preceptivo, por un lado, que hubiese un tipo de letra durante todo el año, pero sobre todo estaba prohibido hacer el registro a cualquier miembro de la junta. Se depositaba la confianza solamente en el escribano y ningún otro podía tener acceso a los libros.

La sustitución del escribano podía, pues, suceder por fallecimiento, impedimento temporal o definitivo del titular.

La solución encontrada en los estatutos para estas situaciones no siempre era muy operativa y, a veces, resultaba difícil y poco rigurosa en los asentamientos. En

${ }^{7}$ Cunha, M. S. (2000). A Casa de Bragança 1560-1640. Práticas senhoriais e redes clientelares. Lisboa: Ed. Estampa, pp 337-382.

${ }^{8}$ Consúltese Cunha, M. S. (2007). «D. Teodósio II, sétimo duque de Bragança. Práticas senhoriais como política de reputação». Monumentos, 27, p. 54.

${ }^{9}$ AMVV, Fundo da Misericórdia, Compromisso de 1577, Livro n²2, f1. 13. 
1600 los cofrades de Vila Viçosa analizaron lo sucedido durante la escritura de fray Francisco Romano en 1599 quien, después de un largo período de enfermedad falleció, siendo sustituido por otro miembro de la junta constatándose que había «tan grande confusión al transcribir las cosas de memoria» que resolvieron hacerlo de forma diferente. Determinaron que, a los 15 días del impedimento del titular, el cofrade sustituto podía registrar directamente en los libros todas las referencias necesarias, evitando así los fallos de memoria y la falta de claridad.

La experiencia aconsejaba alterar el acuerdo en este sentido para que el archivo funcionase con eficacia. «Todos quedaron satisfechos» con la solución encontrada y se sentían esperanzados para agilizar el funcionamiento de un sector importante de la institución ${ }^{10}$.

El capítulo trigésimo sexto determina el número de libros existentes en la cofradía definiendo la composición del archivo. Se estipulaba la existencia de nueve libros: unos para los cofrades, uno para las amonestaciones, un inventario, uno para ingresos y gastos, uno para los presos, otro para las elecciones, uno para los enfermos, uno para los entierros y, por fin, otro para el registro de las actas ${ }^{11}$.

Después de la relación de los libros, el compromiso determinaba la forma de hacer los registros, indicando claramente al escribano la forma de efectuarlos.

Como se constata, la documentación se refería, por un lado, al funcionamiento de la documentación y, por otro, a las obras de caridad practicadas.

La constitución del registro materializaba el crecimiento de estas instituciones y engrandecía la vida de las cofradías y las obras de misericordia llevadas a cabo.

Con la ampliación de la Santa Casa de Vila Viçosa, el registro se volvió más complejo, apareciendo otros libros, como sucedió en la mayoría de las Misericordias.

Razonablemente conservado, el archivo de la cofradía perdió parte de su contenido, sobre todo lo más antiguo y también lo del período de las guerras. Una parte de la documentación de 1640 a 1668 se perdió, así como la de las dos primeras décadas del siglo $\mathrm{XIX}^{12}$.

${ }^{10}$ AMVV, Fundo da Misericórdia, Compromisso de 1577, Livro no 22 fls. 40-41.

${ }^{11}$ AMVV, Fundo da Misericórdia, Compromisso de 1577, Livro n²2, fls. 34-36.

12 Tenemos certeza de que no fue este el único factor. La falta de un espacio adecuado y la poca importancia dada a este sector contribuyeron de la misma forma a dilapidar este patrimonio. Esta situación no fue exclusiva de Vila Viçosa. Lo mismo sucedió en sus análogas. Léase a propósito 
Como Vila Viçosa fue atacada por ejércitos extranjeros en estas dos fechas y la villa se llenó de militares, el archivo sufrió con estas circunstancias y se perdió parte de la documentación ${ }^{13}$. Además el hecho de llevar algunas veces los libros a la casa de algunos cofrades en nada contribuyó a su preservación.

El camino recorrido por cada institución, las fases de desarrollo y las crisis, acaban reflejándose en la memoria escrita y ayudan a comprender la constitución y conservación del archivo ${ }^{14}$.

Durante los siglos XVII y XVIII, los cofrades más de una vez intentaron mejorar las condiciones logísticas del registro, habilitando un espacio para su custodia, sin embargo en esas fechas ya se constata la falta de algunos documentos $^{15}$.

De la misma forma que lo verificado en otras instituciones semejantes, se hicieron inventarios y se tomaron medidas para proteger la documentación, aunque no siempre se haya actuado con total eficacia ${ }^{16}$.

A pesar del cuidado impuesto, por el acuerdo, a los escribanos para elaborar los registros, lo cierto es que no todos lo hacían con el mismo rigor. El hecho de realizarse una vez al año podía contribuir para cierta dejadez y falta de orden en la elaboración de las anotaciones. La resolución de 1600 no contribuía a la responsabilidad del titular del puesto, pues no se le podía culpar de lo que él no había escrito. Si por un lado agilizaba las cosas, por el otro se sufría las consecuencias de haber copiado un sector importante la persona que no era titular del cargo.

En el siglo XVIII, cuando las Juntas no se renovaban anualmente, hubo escribanos que permanecieron durante varios años. Aún así, la continuidad de las

Penteado, P. (2002). «As Misericórdias, contributo para um guia dos Arquivos». In Paiva, J. P. (Coord. Científico). Portugaliae Monumenta Misericordiarum, vol. 1..., p. 123.

13 Araujo, M. M. L. (2008). «Marcas da guerra da Restauração nas Misericórdias portuguesas de fronteira». In MARTinez Millan, J., LOURENÇO, M. P. M. (coords.). Las relaciones discretas entre la Monarquía Hispana y Portuguesa: las casas de las Reinas (siglos XV-XIX). Vol. III. Madrid: Ediciones Polifemo, pp. 2113, 2137, 2148.

${ }^{14}$ Véase a propósito RuAs, J. (2002). «O arquivo». In RuAS, J. (coord.) 500 Anos. Santa Casa da Misericórdia de Estremoz. Estremoz: Santa Casa da Misericórdia de Estremoz, p. 181.

15 Araujo, M. M. L. Dar aos pobres e emprestar a Deus..., p. 52.

16 Para analizar las medidas tomadas por la Misericórdia de Montemor-o-Novo con el fin de preservar su memoria léase FONSECA, J. (2008). «O arquivo histórico da Misericórdia». In RUAS, J. (coord.). A Misericórdia de Montemor-o-Novo. História e Património. Montemor-o-Novo: Santa Casa da Misericórdia de Montemor-o-Novo, pp. 322-323. 
funciones no trajo consigo una organización mejor del archivo ni de las anotaciones en los libros. Antes por el contrario, fue unos de los períodos en los que se constató desinterés y hasta abandono, principalmente en algunas áreas de este sector.

Cuando había varios escribanos en un mismo año, la situación era peor y la calidad de los registros disminuía. Aunque de forma involuntaria, los encargados de copiar los escritos contribuían al desorden al pasar los asuntos tratados a los libros. No se respetaban los márgenes ni la cronología, se repetían los asuntos, de forma que desaparecía la calidad y se instalaba el desorden.

A mediados de 1749 el escribano Francisco Araújo Sampaio Homem de Magalhães comenzó un libro nuevo para registrar las elecciones. Los términos de la apertura del libro se justificaban por la continua y «desordenada confusión que encuentro en todos los libros y sobre todo en los de mayor importancia, en los que se confunden recomendaciones con órdenes, términos y materias que están dispuestos en los libros» ${ }^{17}$. La observación no podía ser más clara: las anotaciones se hacían sin criterio, aun en los libros de mayor responsabilidad.

El aprovechamiento de papel no era una preocupación para los cofrades. Los libros los comparaban en Évora y aunque no eran baratos, los cofrades nunca se preocuparon por el precio. Pensamos que el aprovechamiento de los márgenes $\mathrm{y}$, a veces, la falta de espacio entre los asuntos dependía más del que los escribía que de los criterios establecidos para economizar.

Como el funcionamiento deficiente del archivo era conocido probablemente, algunos asuntos se registraban en varios libros para que no se olvidasen. Recordamos los contratos efectuados con los asalariados, las procesiones de Semana Santa, sobre todo las de los jueves y viernes, y los informes referentes a los soldados tratados en el hospital de la institución.

Al disponer la Santa Casa de un cuerpo de empleados considerable, que era reivindicativo, fue necesario registrar los contratos que tenían con la institución. En julio de 1749, intentando impedir los «abusos fijados por préstamos perjudiciales», la junta directiva consultó «los libros antiguos de esta Santa Casa respecto a los salarios de los empleados, encontrándolos adulterados sin que hubiese constancia de los aumentos por parte de la Junta» ${ }^{18}$ y corrigieron el contrato de algunos. Se

${ }^{17}$ AMVV, Fundo da Misericórdia, Livro de eleições, $\mathrm{n}^{\mathrm{o}}$ 73, fl. 1.

${ }^{18}$ AMVV, Fundo da Misericórdia, Livro para nelle se lançarem os acordaons desta Mesa da Santa Caza da Misericórdia de Vila Viçosa, nº 1, fl. 15v. 
percibe que aun habiendo varios registros, existía mucha confusión en un sector de máxima importancia para la institución.

Conforme se corregían las cláusulas de cada empleado, se hacía más evidente la necesidad de tomar las medidas oportunas. Se supo que el enfermero, al haberle autorizado tener un asno, hacía «negocio de que resulta prejuizo porque indus os pobres a que passa cartas de guía com cabalgadura y con muchos hacía ajustes dándoles solamente una parte y quedándose con la otra sin llevarlos a las Misericordias que es lo que tenía que hacer». Y de la misma forma, sin la debida autorización, obligaba a los pobres a pagarle el agua que les servía ${ }^{19}$.

Si comparamos los libros de la Misericordia de Vila Viçosa con los de otras Santas Casas, encontraremos los mismos problemas, aunque también existen diferencias ${ }^{20}$, sobre todo en lo que se refiere a los asuntos tratados pero también al cuidado, esmero y presentación de los libros. En Vila Viçosa se gastó poco en esta actividad. Solo se conserva una sección a la que el escribano se dedicó con esmero, abriendo cada subcapítulo con un título que el mismo estableció. Se trata del libro de ingresos y gastos de $1728^{21}$.

Hasta el siglo XVIII, los libros de ingresos y gastos contaban con mucha información sobre diferentes aspectos de la actividad que desarrollaba la cofradía. A partir de esa fecha, incluso se volvieron más sintéticos, perdiendo importancia mucha información y las prácticas de caridad que se ejercían dejaron de aparecer. Al mismo tiempo, se instaló la confusión, principalmente a mediados del XVIII, haciendo así la consulta más difícil.

Del período de las invasiones francesas y de la revolución liberal existe poca documentación. Su extravío debe de estar relacionado con el ambiente de guerra que se vivió en la villa y que originó su pérdida. Después de estos acontecimientos, volvió la tranquilidad a la cofradía y los registros se hicieron con mayor continuidad, verificándose una mayor preocupación por la conservación del registro.

19 AMVV, Fundo da Misericórdia, Livro para nelle se lançarem os acordaons desta Mesa..., fl. 16.

${ }^{20}$ Léase para esta materia XAVIER, Â. B.; PAIVA, J. P. (2005). «Introdução». In PAIVA, J. P. (coord.científico), Portugaliae Monumenta Misericordiarum, vol. 4..., p. 19.

${ }^{21}$ Manuel Inácio Pestana analizó la habilidad decorativa del escribano de la época, destacando su originalidad. Léase PESTANA, M. I. (1998). «Arte poética e decorativa num libro setecentista da Misericórdia e outras curiosidades». In Boletim da Santa Casa da Misericórdia de Vila Viçosa, 11, p. 2 . 
Aunque estuvo funcionando con el acuerdo de 1618, desde 1806 hubo modificaciones en el modelo electoral. Por un registro de 1810 se supo que la Misericordia estuvo gobernada, por orden regia, por un proveedor «vitalicio». El resto de los componentes de la junta eran elegidos siguiendo el modelo del acuerdo referido.

Con el Liberalismo, la vida de las Misericordias sufrió muchos cambios, principalmente en el sector administrativo. Una orden de 1823, emitida en cumplimiento de la resolución de 15-3-1800, obligaba a estas cofradías e remitir una relación de todos los bienes al Tribunal de las Capelas da Coroa, teniendo así que elaborar un libro de registro ${ }^{22}$. Posteriormente, en las décadas de los 30 y 40 , más de una vez, el gobernador civil obligó a la Santa Casa a presentar los libros de cuentas y el inventario, en un intento de observar de cerca y controlar la contabilidad.

El acuerdo de 1618 determinaba que el escribano fuese hombre «noble, virtuoso, prudente y de condición», de forma que pudiese tratar «los negocios con seguridad y facilidad». La edad mínima exigida para el ejercicio del puesto continuaba siendo los 40 años, aunque un decreto regio de 25-06-1732 lo había rebajado hasta los 35, determinando que fuese persona con tiempo para poder dedicarse a los intereses de la institución ${ }^{23}$. Determinaba una presencia asidua en la cofradía, mañana y tarde, siempre que fuera posible para poder responder a las necesidades del cargo. A pesar de tener un puesto importante en la Junta directiva, no podía gastar cualquier montante sin la previa autorización de los restantes miembros de la Junta. Lo mismo que en 1577, recaía sobre él la tarea de presidir la institución en ausencia del proveedor. Estaba prohibido mandar «escribir en los libros ninguna cosa de las que concurrían con dote, depósitos, Sentencias y secretos; porque todas esas cosas tenían que ser escritas de su puño y letra ${ }^{24}$, aunque la copia de certificados podía ser hecha por otras personas, sin embargo era necesaria su firma para que fueran válidos. Era función suya también exigir a los mayordomos las cuentas de la capilla y de la bolsa mensualmente y asistir a todas las entregas hechas por la institución.

Cuando estuviese impedido por algún motivo, el proveedor podía sustituirlo por otro miembro de la junta, pero, en conformidad con el acuerdo de 1577, este

22 Archivo de la Santa Casa de Misericordia de Vila Viçosa (en adelante ASCMVV), Rellação das Propriedades da Mizericórdia, 1824, no paginado.

${ }^{23}$ Compromisso da Misericórdia de Lisboa (1619). Lisboa: Pedro Craesbeeck, p. 16.

${ }^{24}$ Compromisso da Misericórdia de Lisboa (1619). Lisboa: Pedro Craesbeeck, p. 17. 
cofrade no podía «escribir nada en los libros», debía anotar lo tratado en un cuaderno para que después el escribano lo copiase en el libro adecuado ${ }^{25}$.

En el caso de muerte o de ausencia prolongada superior a un mes, el escribano era sustituido por su antecesor. Y en el caso de no aceptar este, se contactaba con los de los años anteriores hasta encontrar uno que asumiese el cargo. También los electores podían ser convocados para ocupar el cargo. Este escribano sólo podía ocupar el cargo durante la ausencia del titular. Cuando este regresase, volvía a ocupar el puesto ${ }^{26}$.

Las referencias dejadas en este acuerdo tanto al escribano, como a los tesoreros de los depósitos y al cofrade encargado de las limosnas atestiguan la preocupación por las escrituras de las Misericordias y la necesidad de realizar cuidadosamente algunas de sus secciones.

A pesar de haber adoptado el acuerdo de 1618 no se constatan alteraciones en la forma de procesar la información escrita. En cuanto al archivo no hubo cambios significativos. La gran novedad llega con la creación de la Secretaría y, especialmente, con la contratación de un empleado para llevar a cabo la tarea de escribir.

A lo largo de la Edad Moderna, las actas, los libros de recomendaciones, los de las diversas prácticas de caridad y los de ingresos y gastos configuraron un variado abanico de los asuntos tratados en la Junta: contratos de empleados, enfermos, entierros, fiestas, Semana Santa, presos, huérfanas, elecciones, entrada de cofrades, limosnas a pobres, aceptación de legados, botica, conflictos, riesgos de cofrades, curación de militares, privilegios, alquiler y venta de propiedades, herencias, emisión de «cartas de guia», etc.

La atención dispensada a los militares llevaba consigo un gran trabajo de registro y no siempre estaba completo. El área de los militares exigía atención permanente y un trabajo riguroso, porque el número de soldados era elevado y el flujo de entrada y salida también. No se aceptaban cuentas elaboradas fuera de plazo porque eso supondría, necesariamente, confusión y error. No obstante, si la Misericordia fallaba, la Fiscalía del Ejército era más exacta en la cuentas porque mantenía una contabilidad rigurosa. En 1571, la cofradía al confrontar las cuentas, se encontró con la necesidad de devolver a la Corona más de 6 mil cruzados, por haberlos recibido indebidamente. La Junta reaccionó y dijo que no podía

${ }^{25}$ COMPROMISSO da Misericórdia de Lisboa (1619). Lisboa: Pedro Craesbeeck, p. 18.

${ }^{26}$ COMPROMISSO da Misericórdia de Lisboa (1619). Lisboa: Pedro Craesbeeck, p. 18. 
devolverlos, delegando en el escribano, padre André Inácio da Silva, la tarea de contactar con la Casa Real para conseguir el perdón de la deuda. El escribano «tuvo mucho trabajo», pero consiguió la anulación de la devolución cuando el rei D. José visitó Vila Viçosa ${ }^{27}$.

Las diversas obras de misericordia practicadas se registraban en libros propios, aun así, el escribano las copiaba de nuevo en los libros de ingresos y gastos, añadiendo una vez más el acuerdo de la Junta Directiva, de los enfermos tratados, de los presos asistidos, de los huérfanos criados, de los entierros y de las limosnas dadas en Semana Santa y a lo largo del año. También se hacía mención de las procesiones de semana santa y del lavatorio. Sólo después de este informe se presentaba el libro de ingresos y gastos. El escribano también copiaba el registro diario de ingresos y gastos en cuadernos, y de esas anotaciones elaboraba el libro correspondiente. Era un trabajo arduo que le obligaba repetir los mismos asuntos en varios libros. Tal vez por este motivo o también por mayor comodidad, muchos escribanos llevaban los libros a sus casas y en ellas realizaban los escritos.

A comienzos del siglo XIX, la Misericordia sufrió profundas modificaciones en diversos sectores de su actividad. En el ámbito de la producción escrita, fue nombrado un escribiente, que más tarde se llamó «escriturario», dejando de ser el escribano el único en copiar los asuntos de la cofradía. El reparto de las funciones hasta 1839 , fecha en la que nombraron la primera comisión administrativa, no está claro, pero sí es cierto que el lugar ocupado por el escriturario se sobrepone al del escribano. Se sabe que por lo menos desde 1820 la cofradía disponía de un asalariado para registrar parte de los asuntos de la institución. Las razones que llevaron a contratar este empleado no son conocidas, porque no existen libros de actas para el período de 1800 a 1823 , pero, probablemente, estuvieron asociadas al mayor volumen del servicio y a la necesidad de una persona que actuase como secretario de la institución a tiempo completo. Aparece en este momento la formación de una secretaría en embrión que se desarrolla a lo largo de la centuria y que ganaba adquiriendo más importancia, respondiendo así a una institución más burocratizada y a un Estado más intervencionista y controlador.

La necesidad de una persona dedicada a tiempo integral en la institución para efectuar los registros y para llevar la secretaría fueron los motivos que llevaron a otras Misericordias a contratar tempranamente a un hombre para esos servicios. La Santa Casa de Porto dispuso de un archivero a partir de 1669 no sólo para ayudar al

\footnotetext{
${ }^{27}$ AMVV, Fundo da Misericórdia, Livro para nelle se lançarem os acordaons desta Mesa..., fl. 47.
} 
escribano, sino también para mantener el archivo en orden y no permitir que se perdiesen documentos ${ }^{28}$.

Una de las preocupaciones de la comisión administrativa cuando tomó posesión a finales de 1939 en la Santa Casa de Vila Viçosa fue la entrega del archivo. Los nuevos gobernantes querían conocer la documentación existente para llevar una buena administración. Se percibe la intención: los nuevos gestores conocían bien la importancia de este sector para el gobierno de la institución. Por el registro pasaba toda la vida de la cofradía, no sólo lo que se refería a la asistencia, sino también lo al soporte financiero y a las relaciones con otras entidades, principalmente con el Estado.

Después de haber sido solicitado el inventario al proveedor de aquel momento, éste sólo respondió por la insistencia y para decir que no lo podía entregar «por constar este de muchos y diferentes papeles y porque hasta el día de hoy no existía el correspondiente inventario ${ }^{29}$.

La respuesta demostraba la total falta de colaboración y descontento por el rumbo que llevaba la institución. La intención del gobernador civil era mantener la Junta Directiva activa, atribuyéndola sobre todo funciones religiosas, pero los miembros de la junta se negaron a pactar esas modificaciones y en principio no contestaron, después ocultaron información y, más tarde, acabaron por dimitir, para no pactar con la nueva administración.

Ante esta situación, la comisión administrativa resolvió encargar a António José Pousão la elaboración de un inventario del registro y que el escriturario, a partir de esa fecha, presentase todos los meses la relación de ingresos y gastos a la comisión. Esta, a su vez, determinó establecer dos sesiones semanales (lunes y miércoles) ${ }^{30}$ para examinar la contabilidad de las juntas anteriores y consideró que no era necesario levantar acta en todas las sesiones, sino solamente cuando se considerase oportuno $^{31}$. Debido a este procedimiento nos fue imposible conocer el trabajo y el

${ }^{28}$ Compárese para este tema Freitas, E. A. C. (1995). História da Santa Casa do Porto, vol. III. Porto: Santa Casa da Misericórdia do Porto, pp. 366-369.

29 AMVV, Fundo da Misericórdia, Este libro he destinado para as sessoens da Comissão Administrativa..., 1839-1847, fl. 3.

${ }^{30}$ La periodicidad de las reuniones fue alterada posteriormente, tanto por la junta, como por el nuevo compromiso de 1881.

31 AMVV, Fundo da Misericórdia, Este libro he destinado para as sessoens da Comissão Administrativa..., 1839-1847, fl. 4v. 
resultado del peritaje de la contabilidad de la institución, realizados por la comisión.

António José Pousão era escribano hacía 24 años, cuando, en 1844, solicitó que su lugar lo ocupase su hijo, mayor de 25 años, casado y su ayudante en diversas ocasiones. Reunía, por tanto, las condiciones para que depositasen en él la confianza para el ejercicio del cargo. Añadía además la necesidad que su hijo tenía del empleo. La comisión administrativa, procediendo como lo hacían las antiguas juntas, y haciéndolo constar, le concedió el cargo ${ }^{32}$.

Para el susodicho cargo era importante sintonía con las actitudes de las antiguas Juntas, como forma de calmar las tensiones internas y obtener algún consenso.

El traspaso de los oficios de padres a hijos era común en algunos sectores de la cofradía. Era también frecuente, que los hijos comenzasen haciendo el trabajo de forma gratuita y así más tarde accedían al cargo. Este período servía para que fuesen conociendo las exigencias de la profesión y para poder ser observados por la institución. El período de prueba era importante para que los cofrades evaluasen las características del sujeto, así como, sus habilidades para el cargo.

La burocratización de los servicios y las imposiciones del Liberalismo obligaron a tener más de una persona, sobre todo cuando el titular ya no podía efectuar la tarea con eficacia. Tal vez fue por esta razón que António José Pousão era auxiliado por su hijo, aunque también fuese frecuente la prestación gratuita del servicio como la forma de abrirse el camino para un contrato futuro, como ya referimos.

En el momento de la elección, en julio de 1865, el escribiente «encontrándose bastante sobrecargado» debido al «intenso servicio» de las pautas de la elección, pidió al tesorero que hiciese el trabajo que le correspondía, pues, por su mucha edad y enfermedad no podía realizarlo ${ }^{33}$. Apenas habían pasado 21 años desde que hicieron el contrato de escribiente. La mucha edad alegada en 1865 demuestra que cuando entró como efectivo en la Misericordia no era muy joven y no gozaba de buena salud ${ }^{34}$.

32 AMVV, Fundo da Misericórdia, Este libro he destinado para as sessoens da Comissão Administrativa..., 1839-1847, fls. 33v.-34.

33 Arquivo Distrital de Évora (en adelante ADE), Fundo do Governo Civil, cx.- 1013, Actas da eleição da Misericórdia de Vila Viçosa, 1865, no paginado.

${ }^{34}$ En 1552, el escribiente pidió permiso a la comisión administrativa para «ir a unos baños de mar», dejando al fiel en su lugar. AMVV, Fundo da Misericórdia, Livro das Actas das sessões da 
A partir de 1835, hubo sectores de la vida de la cofradía que cobraron importancia en lo que respecta a los registros. Sobre todo los cobros de rentas y fueros, y el hospital en sus diferentes sectores.

Con deudas atrasadas en el área de cobros, prácticamente no había sesión de la junta y de la comisión administrativa, en la que asunto no fuese analizado. Hubo reuniones dedicadas exclusivamente a esta materia, pues tal era la urgencia de tomar decisiones. Este asunto se mantuvo presente para establecer estrategias de cobro, el perdón parcial o total de la deuda, en algunos casos, nuevos arrendamientos, realización de otros contratos, y, en última instancia, quejas, falta de liquidez, malas cosechas, carestía y arcas vacías. A partir de 1866, con la ley de desamortización, los fueros disminuyeron significativamente y el asunto prácticamente desapareció de las actas.

Al mismo tiempo que se trataba de los fueros, se manifestaban preocupaciones y se tomaban medidas en el ámbito del hospital. Las actas demuestran una institución preocupada por el sector de la salud y la imposibilidad de mantenerlo al nivel deseado. El internamiento y curación de los militares dio continuidad a una intensa relación entre la Misericordia y el Gobierno, poco visible en las actas, pero que ocupaba casi por entero los libros de correspondencia ${ }^{35}$. Los oficios expedidos y recibidos certifican esa vinculación y prueban las dificultades que tenía la cofradía para pagar los gastos realizados. Además acreditan la adopción de diferentes actitudes por parte de la Santa Casa: unas veces arrogante, reivindicativa y amenazadora y otras agradecida y dispuesta a seguir curando a los militares enfermos.

En los libros de correspondencia, así como en los de las actas, aunque en estos últimos solo de forma indirecta, aparece también el intercambio de correspondencia con el administrador del municipio. Muy intensa entre 1835 y 1685 , se normalizó posteriormente, ganando nuevo aliento en la última década de la centuria, cuando se estableció otra comisión administrativa. Por otro lado, durante este período los asuntos son de poco relieve y se refieren casi exclusivamente a las elecciones y a la contratación de mercancías en la plaza pública.

Meza da Santa Caza da Mizericórdia 1847-1857, fl. 51. La enfermedad no fue identificada, pero se aconsejaba una temporada fuera y tratamiento con baños de mar.

${ }^{35}$ Estas instituciones mantuvieron siempre una comunicación intensa con diferentes entidades e instituciones públicas y privadas, lo que subrayaba la importancia de su archivo. Léase a propósito LOPES, Maria Antónia (2005). «As comunicações nas Misericórdias». Separata de As Comunicações Na Idade Moderna. pp. 177-210. 
Con el cambio de siglo, el asunto más tratado en las actas fue el de la farmacia, tanto el contrato con el farmacéutico, como la viabilidad de la propia farmacia.

El cargo de secretario le obligaba a elaborar los presupuestos anuales: ordinarios y adicionales, en los que figuraban las asistencias, los salarios pagados, las rentas recibidas, los gastos y la presentación mensual de las cuentas de la junta. Esta última obligación solamente servía para cumplir una formalidad, ya que nunca se produjo ninguna deliberación de las mismas, aprobándolas siempre sin reparos.

En la segunda mitad del diecinueve, parte de la contabilidad se hizo más viable por la adopción de modelos impresos, como sucedió, por ejemplo, com los presupuestos y las facturas.

El puesto de secretario y sus funciones sufrieron bastante las dificultades internas y fueron el resultado de los equilibrios conseguidos. En 1849, Manuel Maria Matroco solicitó a la Misericordia ocupar el puesto de fiel ${ }^{36}$, cuando todavía estaba en funciones José Elisardo Pombeiro ${ }^{37}$.

Cuando solicitó el puesto, Matroco ya sabía que el fiel iba a ser despedido, para ocupar el puesto de «amanence» en el Concejo lo que ocurrió poco después. A pesar de esto, no fue aprobado, a causa de la división de la junta, pues había cofrades que defendían el final de este puesto y otros que deseaban mantenerlo. Como no era cofrade, Matroco tenía a su favor esta situación, pero sin saber qué hacer, la junta pidió ayuda al Gobierno Civil que ordenó la provisión del solicitante en su puesto. La junta se amotinó y varios cofrades se opusieron a la orden del gobernador civil, siendo su cabecilla el cofrade Francisco Alves Torres, estando, como afirmaba el proveedor, en «perfecta oposición», reclamando «rápidas y eficaces disposiciones para que se otorgase el puesto al empleado ${ }^{38}$. El proveedor se esforzaba en cumplir las órdenes que le llegaban de Évora, pero la resistencia interna no facilitaba su decisión y voluntad.

\footnotetext{
${ }^{36}$ Ese puesto fue creado por la comisión administrativa, en 1840, porque necesitaban un hombre de su confianza que asegurase el trabajo hecho anteriormente por el cofrade del mes. Se le exigía presencia diaria en el hospital y la supervisión de todos los asuntos, tarea que obligaba su presencia durante casi todo el día en la institución.

${ }^{37}$ Este empleado fue capitán de infantería del ejército de D. Miguel y después de 1834 se instaló en Vila Viçosa, donde se casó. Durante el tiempo que sirvió como fiel pintó de nuevo la bandera de Nuestra Señora de la Misericordia de la cofradía. Este estandarte se llevaba en los entierros y en las procesiones. Véase EspancA, J. J. R. (1988). Memórias de Vila Viçosa, nº 33. Vila Viçosa, pp. 101102.

${ }^{38}$ ADE, Fundo do Governo Civil, cx. 983, Orçamento de receita e despesa 1850, no paginado.
} 
Además de no estar de acuerdo con la permanencia del puesto, había otras solicitudes de cofrades, lo que probablemente ayudó a que continuase la polémica, sobre todo la de Francisco Alves Torres. La junta entregó el puesto a Manuel Matroco y posteriormente fue confirmado por el consejo del distrito.

Después del relevo de la nueva comisión administrativa de 1865, la junta elegida deseaba acabar con el modelo anterior y en su primera sesión de trabajo discutió la continuidad de los puestos adjuntote fiel y de contable. Según el proveedor, los miembros de la junta pretendían «hacerse cargo de la administración, en conformidad con los antiguos usos y costumbres de la casa» ${ }^{39}$. En cuanto al escriturario considerando que la institución debía mantener «bien actualizada la complicadísima documentación» y cumplir lo establecido, «es obvio que el puesto del escriturario con las condiciones establecidas, solamente para escribir y copiar lo que se le solicitaba, debía ser sustituido ${ }^{40}$. La cuestión era el mantenimiento de dos puestos, cuando la situación financiera de la cofradía aconsejaba disminuir los gastos. Además el fuerte deseo de los cofrades de asumir los antiguos puestos era también un factor importante.

Por otro lado, los cofrades reconocían la necesidad de un hombre con disponibilidad y aptitudes para una tarea escrituraria complicada, minuciosa y diaria. Discutían, pues, si entre ellos habría alguno que aceptase el cargo sin la correspondiente remuneración. Los cofrades pretendían las antiguas tareas, pero no poseían la capacidad para realizarlas, como, por ejemplo, el escribano, ni querían hacerlas sin retribución.

El trabajo exigido al escribiente era excesivo y le obligaba a trabajar diariamente, por cuanto

"[...] este sistema, achava-se na actualidade montado, com tal regularidade, que todos os dias se conhece dos diferentes mapas o movimento dos doentes, os géneros que estavam, os que se consumiram, quais os remédios que se aplicavam [...], as despesas não podem ser descritas comulativamente, cada uma pertence á sua classe [...], finalmente seria impraticavel, se não impossivel fazer-se a escrituração adoptada neste hospital sem um empregado, devidamente subsidiado, que dirija e formule diariamente a contabilidade, e a escrituração segundo as ordens superiores,

39 AMVV, Fundo da Misericórdia, Livro de actas das sessões da comissão administrativa da Misericórdia 1863-1868, fl. 35v.

40 AMVV, Fundo da Misericórdia, Livro de actas das sessões da comissão administrativa da Misericórdia 1863-1868, fl. 35v. 
e que igualmente se responsabilize, por todo o expediente debaixo da inspecção do provedor e escrivão da mesa» ${ }^{41}$.

Se pretendía suprimir los puestos de trabajo del fiel y del escriturario y crear uno que reuniese las dos tareas. La Junta acordó esta propuesta y contrató a un nuevo empleado, llamado Mayordomo de la Casa, con el sueldo anual de 57.000 reales y 90 alqueires. Escogieron para el puesto a Manuel Matroco ${ }^{42}$.

El cargo de escribano se mantuvo con funciones muy reducidas, una vez que la mayor parte del trabajo de escribir pasó a manos del Mayordomo de la Casa.

Se había puesto un modelo de gestión que ya no se compaginaba del todo con el acuerdo y que procuraba responder a las exigencias de los nuevos tiempos.

Obligada a enviar la relación de las cuentas con regularidad al administrador del ayuntamiento y a responder las solicitudes que éste le hacía de los libros de ingresos y gastos, inventario y otros, la Misericordia conocía muy bien la importancia de una respuesta a tiempo y eficaz para no ser importunada y acusada de inobservancia de la ley.

Manuel Matroco fue el secretario que acompañamos durante más tiempo. Estuvo mucho tiempo en la institución y siempre fue considerado como un buen servidor. Entró como adjunto y pasó posteriormente a secretario, cargo que ejerció hasta 1903, por haber pedido la dimisión. Entonces se decía que era de edad avanzada, aunque ya tenía un sustituto, Luis Silveira, secretario municipal, había llegado la hora de jubilarse, aunque estaba dispuesto a continuar hasta que el puesto estuviese ocupado ${ }^{43}$. En aquel momento, Manuel Matroco tenía 83 años y declaraba haber servido a la Santa Casa durante 54 años seguidos y ser mayor para continuar con esa tarea ${ }^{44}$. La Misericordia aceptó su petición, agradeció el celo y empeño con el que siempre trabajó en la institución y decidió abrir concurso público para proveer el puesto ${ }^{45}$ y colocó a Luis Silveira, único concurrente.

41 AMVV, Fundo da Misericórdia, Livro de actas das sessões da comissão administrativa da Misericórdia 1863-1868, fls. 36-36v.

42 AMVV, Fundo da Misericórdia, Livro de actas das sessões da comissão administrativa da Misericórdia 1863-1868, fl.37.

${ }^{43}$ ASCMVV, Correspondência, documento separado, sin paginar.

44 AMVV, Fundo da Misericórdia, Actas da Mesa Administrativa da Misedricórdia 1896-1907, fl. 78 .

${ }^{45}$ Diario do Governo, 26 de Setembro de 1903, n ${ }^{\circ} 215$, p. 3308. O salario estipulado era de 105 mil réis anuais. 
¿Pero quién era Manuel Matroco? ¿Y qué preparación tenía para haber ocupado un puesto tan importante a lo largo de varias décadas en la Santa Casa? Fue, de joven, alumno del colegio de reyes, era un hábil decorador y además de adjunto y escribano de la Misericordia, había sido también escribano del ayuntamiento y de la administración del municipio. También fue colaborador del padre Joaquim José Da Rocha Espanca en la coordinación de la biblioteca del municipio ${ }^{46}$. Reunía, por tanto, un conjunto de aptitudes y también apoyos entre los poderosos de la villa, que facilitaron la boda de su hija con una de las familias más importantes del lugar.

El hecho de haber pasado por la administración del municipio y por la Asamblea le preparó para el puesto en la Misericordia. La práctica y los conocimientos que adquirió contribuyeron para mantenerse como mayordomo de la Santa Casa durante más de medio siglo, respondiendo con eficacia a los desafíos de una escrita cada vez más compleja.

Este secretario, aunque desease acabar sus «días al servicio de esta institución», se sentía a los 83 años «enflaquecido». En ese tiempo, acudía ya a un auxiliar, a sus expensas, para que le sustituyese y ayudase cuando le hiciese falta. La Junta consideró al secretario un hombre «probo», celoso y cumplidor, elogió sus cualidades y dedicación al trabajo y aceptó su petición ${ }^{47}$.

Como secretario, Manuel Matroco fue un secretario ejemplar. Nunca hubo una crítica sobre su trabajo, no faltaba a las reuniones y los términos demuestran que ejercía el oficio com esmero y dedicación.

Desde el momento que le aceptaron el pedido, Manuel Matroco se debe haber ausentado de la institución, una vez que los registros comenzaron a firmarse por el secretario substituto Luis da Silveira. Sólo después de algunos meses, este hombre asumió el puesto con pleno derecho, esto es, cuando terminó el concurso.

Aunque estuviese desde mucho tiempo funcionando, la secretaria sólo adquiere fuerza de ley en los estatutos de 1881. Se trata de una dependencia administrativa que respondía a las exigencias de una institución más burocratizada y con las necesidades de mantener un expediente actualizado y eficaz. Por eso, se la creía como una repartición central, local para donde convergía el despacho y la resolución de todos los servicios. Estaba constituida solamente por un funcionario,

46 EspancA, T. (1974). «Figuras Grada e Casario Antigo dos Arruamentos de Vila Viçosa» $A$ cidade de Évora, $\mathrm{n}^{\circ}$ 57, p. 227.

${ }^{47}$ AMVV, Fundo da Misericórdia, Actas da Mesa Administrativa da Misericórdia 1896-1907, fls. 78v.-79. 
que debía asistir a la sesiones de la Junta y labrar sus actas, que además firmaba, despachar todos los asuntos de acuerdo con las órdenes de los componentes de la junta, elaborar las actas de las elecciones y escribir los libros de registro. Más que el escribano, el secretario estaba disponible en el horario de atendimiento tanto para los de los miembros de la junta, como para el público que intervenía con la institución. La Misericordia disponía de una sala de espera donde esperaban las personas que iban a tratar con el secretario. Tenía además la función de custodiar el archivo. En 1870, el archivo estaba en una dependencia llamada «sala del Archivo» y los libros se guardaban en un "gran armario» ${ }^{48}$, de la misma forma que sucedía en otras muchas Santas Casas. Los miembros de la Junta estaban impedidos por los estatutos dar órdenes personalmente al secretario, y tampoco podían retirar libros u otros documentos del archivo ${ }^{49}$.

La prohibición de sacar libros y papeles del archivo apareció por primera vez en este acuerdo y demuestra no sólo el valor que la memoria escrita alcanzó en la Santa Casa, así como la necesidad de preservarla.

Los cofrades conocían bien la necesidad de un archivo preservado, seguro, que funcionase, tanto para lo cotidiano de la institución, como para las circunstancias de mayor complejidad, como, por ejemplo, probar las cuentas al tribunal. Por eso, decidieron tomar medidas para su preservación. En Vila Viçosa, no pocas veces se constató la pérdida de documentos $\mathrm{y}$, en el fondo, el poco cuidado dispensado al registro. Todavía, a pesar de haberse perdido una parte importante de su memoria, el archivo existente ofrece la posibilidad de dar a conocer una institución con más de 500 años de historia.

\section{EPÍLOGO}

El estudio de la producción escrita de la Santa Casa de Vila Viçosa a largo plazo permitió conocer el marco en el que se realizó así como a sus principales autores. Aunque estas instituciones fueron conscientes de la importancia de su archivo y solamente un cofrade, y más tarde un secretario, estuvieron encargados de esta tarea, no siempre el cuidado y las medidas adoptadas fueron eficaces para conservarlo. Se observa, a veces, una menor importancia otorgada a este sector a pesar de que estuviesen reguladas las condiciones de actuación de los hombres encargados de la escritura.

48 ADE, Fundo do Governo civil, cx. 984, peça nº 33, Orçamentos da receita e despesa 18701871, fl.3.

${ }^{49}$ AMVV, Fundo da Misericórdia, Compromisso de 1881, no paginado. 
A pesar de que fueron casos aislados, se tiene constancia de situaciones en las que los documentos se perdieron, se comprobó una falta de precisión en la redacción de algunos registros y se constató cierta confusión en la sección de archivo. Las medidas tomadas intentaron resolver este problema y poner orden en un sector muy importante de la institución.

A medida que la Hermandad iba creciendo, aumentó el volumen de trabajo del cofrade encargado de la escritura, de manera que en el siglo XIX, no sólo este hecho sino principalmente su complejidad, obligó a la institución a contratar a un empleado para redactar toda la documentación y mantener en orden el archivo.

\section{BIBLIOGRAFIA}

ARAÚJO, Maria Marta LOBO DE (2008). «Marcas da guerra da Restauração nas Misericórdias portuguesas de fronteira», en MARTíNEZ MILLÁN, Lourenço, Maria Paula MARÇAL (coords.), Las Relaciones Discrestas entre las Monarquia Hispana y Portuguesa: las Casas de las Reinas (siglos XV-XIX), vol. III, Madrid, Ediciones Polifemo, pp. 2113, 2137, pp. 2129-2150.

ARAÚJo, Maria Marta LoBo De (2000). Dar aos pobres e emprestar a Deus: as Misericórdias de Vila Viçosa e Ponte de Lima, Barcelos, Santa Casa da Misericórdia de Vila Viçosa e Santa Casa da Misericórdia de Ponte de Lima, 2000.

Compromisso da Misericordia de Lisboa (1619). Lisboa, Pedro Craesbeeck.

Cunha, Mafalda SoARes DA (2000). A Casa de Bragança 1560-1640. Práticas senhoriais e redes clientelares, Lisboa, Ed. Estampa.

DO COMPROMISSO da confraria da Sancta Caza da Misericórdia de Lisboa fundada pela rainha D. Leonor de Lencastre (1929). Caldas da Rainha, Tip. Caldense.

Espanca, José Joaquim DA Rocha (1988). Memórias de Vila Viçosa, nº 33, Vila Viçosa, Câmara Municipal de Vila Viçosa.

EsPanCA, Túlio (1974). «Figuras Gradas e Casario Antigo dos Arruamentos de Vila Viçosa», in A cidade de Évora, ${ }^{\circ}$ 57, 1974.

FONSECA, Jorge (2008). «O arquivo histórico da Misericórdia», in RUAS, João (coord.), $A$ Misericórdia de Montemor-o-Novo. História e Património, Montemor-o-Novo, Santa Casa da Misericórdia de Montemor-o-Novo, pp. 321-328.

PaIVA, José Pedro (coord. científico) (2005). Portugaliae Monumenta Misericordiaram, vol. 4, Lisboa, Centro de Estudos de História Religiosa; União das Misericórdias Portuguesas.

Penteado, Pedro (2002). «As Misericórdias, contributo para um guia dos Arquivos», in PaIVA, José Pedro (coord. científico), Portugaliae Monumenta Misericordiarum, vol. 1, Lisboa, Centro de Estudos de História Religiosa; União das Misericórdias Portuguesas, p. 131-280.

Penteado, Pedro (1998). «Os arquivos e a História das Misericórdias em Portugal: problemas e perspectivas», in Oceanos, $\mathrm{n}^{\circ} 35$, pp. 91-96. 
PESTANA, Manuel Inácio (1988). «Arte poética e decorativa num livro setecentista da Misericórdia e outras curiosidades», in Boletim da Santa Casa da Misericórdia de Vila Viçosa, 11, pp 1-2.

RUAS, João (2005). «O arquivo», in RUAS, João (coord.), 500 Anos. Santa Casa da Misericórdia de Estremoz, Estremoz, Santa Casa da Misericórdia de Estremoz, 2002, pp. 181-189.

XAVIER, Ângela BARreto; PAIVA, José Pedro, «Introdução», in PAIVA, José Pedro (coord. científico), Portugaliae Monumenta Misericordiarum, vol. 4, Lisboa, Centro de Estudos de História Religiosa; União das Misericórdias Portuguesas, pp. 7-30. 